\title{
MONITORAMENTO DA ATIVIDADE BACTERIANA DE UM SISTEMA DE LODOS ATIVADOS BARDENPHO POR MEIO DA RESPIROMETRIA
}

\section{CONTROL OF REACTION SLUDG'S SYSTEM BACTERIAN ACTIVITY - BARDENPHO THROUGH RESPIROMETRY}

\begin{abstract}
ADRIANA GUIMARÁES COSTA
Engenheira Sanitarista. Mestre em Engenharia Civil/Saneamento pela Universidade Federal da Paraíba. Coordenadora da Area de Meio Ambiente e Docente do Departamento de Meio Ambiente do Centro Federal de Educação Tecnológica do Pará (CEFET-PA)
\end{abstract}

\section{ANDRÉA FAGUNDES FERREIRA}

Engenheira Sanitarísta e Ambiental. Mestre em Engenharia Sanitária e Ambiental. Docente do Centro Federal de Educação Tecnológica do Pará (CEFET-PA) e Docente da Universidade da Amazônia (UNAMA)

\begin{abstract}
ADRIANUS VAN HAANDEL
Professor do Departamento de Engenharia Civil do Centro de Ciências e Tecnologia da Universidade Federal da Paraíba. $\mathrm{PhD}$ em Engenharia Civil/Saneamento
\end{abstract}

Recebido: 15/07/05 Aceito: 26/10/06

\section{RESUMO}

Nos sistemas aeróbios de tratamento de águas residuárias, o oxigênio é um elemento fundamental para que a massa bacteriana possa metabolizar o material orgânico e oxidar compostos como a amônia. Para o acompanhamento desse processo pode ser utilizada a respirometria. Nesta pesquisa, os objetivos são: (1) avaliar a influência da interrupção da aeração sob a atividade das bactérias de sistemas do tipo Bardenpho; (2) estudar a influência do $\mathrm{pH}$ na capacidade oxidativa das bactérias nitrificantes; (3) conhecer a faixa de $\mathrm{pH}$ ideal para o desenvolvimento das bactérias nitrificantes; e (4) observar a confiabilidade da respirometria no monitoramento da atividade bacteriana. Pôde-se concluir que (1) a capacidade metabólica sofre uma redução gradual na medida em que se aplica um período mais longo sem aeração, (2) o pH influenciou diretamente a atividade das nitrificantes, de forma distinta para a oxidação a nitrito e na oxidação a nitrato, e (3) a respirometria foi uma ferramenta muito útil para avaliar a atividade bacteriana e os sistemas de lodo ativado.

PALAVRAS-CHAVE: Bardenpho, respirometria, interrupção da aeração, processo de nitrificação.

\section{ABSTRACT}

In the sewage water treatment aerobic systems oxygen is a fundamental element for the bacterial mass to be able to metabolize organic matter and oxidize compounds such as ammonia. Respirometry can be used in the follow-up of such process. The goals of this research are: (1) to assess the influence of interrupting aeration under Bardenpho-type systems bacterial activity; (2) to study on the influence of $p H$ in the oxidative capacity of nitrifying bacteria; (3) to establish the ideal $\mathrm{pH}$ rate for developing nitrifying bacteria; (4) to observe the reliability of respirometry in monitoring the bacterial activity. The conclusions achieved were that (1) the metabolic capacity is gradually reduced as a longer period without aeration is applied, (2) the $\mathrm{pH}$ directly influenced the activity of nitrifying bacteria in a distinct manner for both nitrite and nitrate oxidation, and (3) respirometry was a very useful tool for assessing bacterial activity and activated sludge systems.

KEYWORDS: Bardenpho, respirometry, aeration interruption, nitrification process.

\section{INTRODUÇÃO}

Na maioria dos sistemas aeróbios, o oxigênio é transferido da atmosfera para a fase líquida do sistema de tratamento por meio de aeradores mecânicos que normalmente funcionam com motores elétricos. Para manter a população bacteriana viva e com boa capacidade metabólica, a disponibilidade de oxigênio faz-se necessária. Contudo, pode haver, na prática, interrupção da aeração, seja por problemas ocasionais na distribuição da energia elétrica ou devido a interrupções planejadas em horários de preço elevado de energia elétrica. Por outro lado, é possível que durante determinados períodos não haja carga orgânica (p.e. no caso de não haver efluentes industriais nos fins de semana), de modo que conviria, em princípio, desligar os aeradores para reduzir o consumo de energia. Por esta razão é de interesse avaliar que influ- ência exerce a interrupção da aeração sobre a sobrevivência de lodo ativo e sobre a atividade deste logo após a interrupção.

Por outro lado, em sistemas aerados de tratamento de esgotos, o oxigênio também é utilizado na oxidação de compostos como a amônia, denominado de nitrificação. Quanto ao processo de nitrificação, Downing et al (1964) estabeleceram que os dois passos fundamentais que podem ser descritos 
pela cinética de Monod, típicos para processos biológicos, mostraram que a cinética da nitrificação depende de uma variável operacional (a idade do lodo) e de três constantes: (1) a taxa de crescimento máximo de bactérias nitrificantes, como Nitrosomonas e Nitrobacter, (2) a constante de decaimento destas bactérias e (3) a constante de meia saturação. Van Haandel e Marais (1999) mostraram que na cinética de Monod a constante mais importante é a taxa máxima de crescimento de nitrificantes, não somente porque esta constante tem muito mais influência sobre a taxa de nitrificação do que as outras constantes, mas também porque se mostra muito mais influenciada pela composição e pela origem da água residuária. Por estas razões, necessita-se de um método experimental que permita a determinação da taxa máxima de nitrificadores de maneira expedita e precisa.

Para o desenvolvimento do presente estudo, a Taxa de Consumo de Oxigênio (TCO) foi acompanhada por meio do respirômetro. As amostras utilizadas eram provenientes de um sistema do tipo Bardenpho, o qual recebe parte do efluente doméstico da cidade de Campina Grande (PB), tendo como objetivos (1) a avaliação da atividade de bactérias heterotróficas mediante períodos de interrupção da aeração, (2) a avaliação da atividade de bactérias autotróficas, mediante a variação de $\mathrm{pH}$, e (3) observar a confiabilidade da respirometria no acompanhamento da atividade bacteriana, em sistemas aeróbios.

\section{MATERIAL E MÉTODOS}

\section{Princípio do teste da respirometria}

No presente trabalho, verificou-se a atividade bacteriana, tendo-se como recurso o uso da respirometria, através da qual utiliza-se um medidor de oxigênio ligado ao respirômetro acoplado a um computador. Através do uso de um software desenvolvido especialmente para esta finalidade, obtêm-se dados da concentração de oxigênio em função do tempo e, após um tratamento estatístico, estes dados permitem o cálculo da taxa de consumo de oxigênio (TCO). Estes dados são armazenados no computador para a produção de respirogramas: diagramas da TCO em função do tempo. Para a determinação confiável da TCO, é preciso haver um consumo de oxigênio de 2 a $3 \mathrm{mg} / \mathrm{l}$ (van Haandel e Marais, 1999). O princípio do teste é simples: o computador controla a aeração ligando os aeradores quando a concentração de OD é menor que um valor de referência inferior (por exemplo $1,0 \mathrm{mg} / \mathrm{l}$ ), aumentando a concentração de OD. Quando esta chega ao valor de referência superior (por exemplo 3,0 mg/l), a aeração é interrompida e observa-se a diminuição da concentração de OD devido à respiração. Ao atingir novamente o valor de referência inferior, a aeração é ligada novamente e inicia-se outro ciclo. Desta maneira, determina-se a TCO semicontinuamente (van Haandel e Catunda, 1982). A Figura 1 mostra um esquema do sistema automatizado de aquisição de dados da TCO em função do tempo.

\section{Característica do sistema- piloto utilizado}

O sistema utilizado para a investigação experimental era do tipo Bardenpho em escala de demonstração $\left(6 \mathrm{~m}^{3}\right)$ que trata $500 \mathrm{l} / \mathrm{h}$ de esgoto bruto municipal de Campina Grande, mantendo-se uma idade de lodo de 7,8 dias, o suficiente para haver nitrificação e desnitrificação eficientes no sistema. As condiçôes operacionais e a composição do esgoto são apresentadas no Quadro 1.

\section{Avaliação da atividade das bactérias heterotróficas}

Para a avaliação da atividade bacteriana após a interrupção da oxigenação, foi coletada uma amostra de

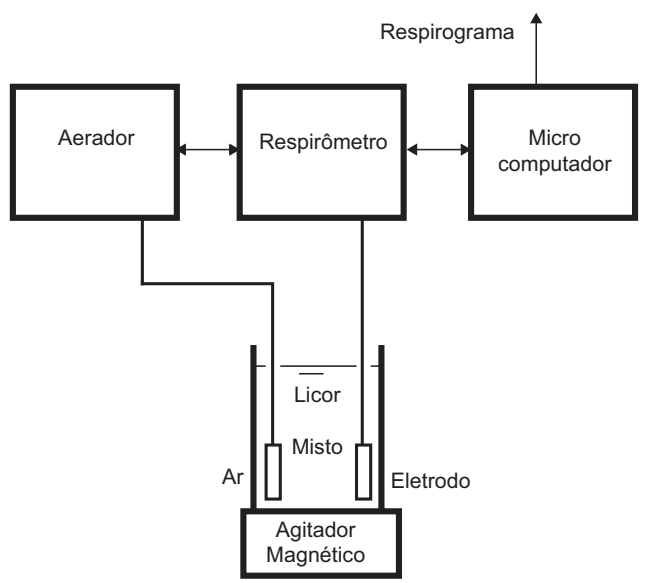

Figura I- Esquema do equipamento para geração de respirograma

Quadro I - Condições operacionais e caracterização do afluente e efluente do sistema gerador de lodo

\begin{tabular}{|c|c|c|c|c|c|}
\hline \multicolumn{2}{|c|}{ Condiçôes operacionais } & \multicolumn{4}{|c|}{ Valores médios do afluente e efluente do reator } \\
\hline Parâmetro & Valor & Parâmetro & Afluente & Reator & Efluente \\
\hline $\begin{array}{l}\text { Volume do Reator } \\
\qquad\left(\mathrm{m}^{3}\right)\end{array}$ & 6 & $\mathrm{DQO}(\mathrm{mg} / \mathrm{l})$ & 327 & & 47 \\
\hline $\begin{array}{l}\text { Vazão do Afluente } \\
\qquad\left(\mathrm{m}^{3} \cdot \mathrm{d}^{-1}\right)\end{array}$ & 12 & TKN (mg/l) & 38 & & 3 \\
\hline $\begin{array}{l}\text { Vazão do Lodo de } \\
\text { Retorno }\left(\mathrm{m}^{3} \cdot \mathrm{d}^{-1}\right)\end{array}$ & 0,77 & $\mathrm{NH}_{3}(\mathrm{mg} / \mathrm{l})$ & 27 & & 1 \\
\hline Idade do Lodo (d) & 7,8 & $\mathrm{NO}_{3}(\mathrm{mg} / \mathrm{l})$ & $<1$ & & 16 \\
\hline Temperatura $\left({ }^{\circ} \mathrm{C}\right)$ & 25 & Alc (mg/l) & & & \\
\hline \multirow{3}{*}{$\begin{array}{c}\text { Número de } \\
\text { determinações }\end{array}$} & 30 & $\mathrm{pH}$ & 7,5 & & 7,2 \\
\hline & & STS $(\mathrm{mg} / \mathrm{l})$ & & 1370 & \\
\hline & & SVS (mg/l) & & 1022 & \\
\hline
\end{tabular}


lodo ativado de 50 litros. Esta amostra era aerada por um período de $3 \mathrm{~h}$ para remover qualquer substrato que pudesse estar absorvido ou adsorvido ao lodo, observando-se que, de fato, na terceira hora a TCO da amostra era praticamente constante. Foram determinadas as concentraçóes de DQO afluente e efluente, bem como a concentração de sólidos em suspensão voláteis, presentes no lodo. $\mathrm{O}$ procedimento descrito foi repetido por três vezes a fim de se confirmar o resultado obtido e obter maior confiabilidade no experimento. Estes são os elementos necessários para calcular a composição teórica do lodo (fração ativa, resíduo endógeno e lodo inerte) e assim tem-se condiçôes de se calcular teoricamente qual é a TCO da respiração endógena usando-se o modelo de lodo ativado de van Haandel e Marais (1999).

Depois da aeração inicial interrompeu-se o fornecimento de oxigênio ao lodo e observou-se a TCO mínima (da respiração endógena) e máxima (com acetato, material prontamente biodegradável), bem como a TCO máxima da nitrificação, da seguinte maneira: Diariamente era retirada uma batelada de 1 litro da amostra inicial para determinação da TCO. Ao atingir a TCO endógena, a batelada era dividida em duas partes iguais e a uma adicionava-se uma concentração de $170 \mathrm{mg} / \mathrm{l}$ (como DQO) de acetato de sódio e à outra uma concentração de $38 \mathrm{mg} / \mathrm{l}$ de cloreto de amônio. O substrato era diluído com a própria amostra para assegurar que não seria fornecido nenhum outro substrato ao lodo. Determinou-se então a TCO nas bateladas durante o metabolismo destes dois substratos.

\section{Cinética de nitrificação e métodos experimentais para sua determinação}

Neste estudo, foi considerada a cinética proposta por Downing et al (1964), e utilizada por van Haandel e Marais (1999), a qual mostrara que a concentração residual de amônia em um sistema de nitrificantes (representadas pelas Nitrosomonas e Nitrobacter) é dada por:

$\mathrm{N}_{\mathrm{a}}=\mathrm{K}_{\mathrm{n}}\left(\mathrm{b}_{\mathrm{n}}+1 / \mathrm{R}_{\mathrm{s}}\right) /\left(\mu_{\mathrm{m}}-\left(\mathrm{b}_{\mathrm{n}}+1 / \mathrm{R}_{\mathrm{s}}\right)\right)$

onde:

$\mathrm{N}=$ concentração residual de amônia $\left(\mathrm{mgN} . \mathrm{l}^{-1}\right)$ $\left(\operatorname{mgN} .1^{-1}\right)$

$\mathrm{K}$ = constante de meia saturação

$\mathrm{b}_{\mathrm{n}}=$ constante de decaimento de Nitrosomonas $\left(\mathrm{d}^{-1}\right)$

$\mu_{\mathrm{m}}=$ taxa máxima de crescimento de Nitrosomonas $\left(\mathrm{d}^{-1}\right)$

$\mathrm{R}_{\mathrm{s}}=$ idade de lodo no sistema de lodo ativado (d).

Van Haandel e Marais (1999), usando dados de vários pesquisadores, mostraram que a constante mais importante, dentre as três que descrevem a nitrificação, é a taxa máxima de crescimento de Nitrosomonas. Por esta razão, a determinação experimental desta constante é de maior importância. Tradicionalmente, determina-se o valor de $\mu_{m}$ em sistemas de lodo ativado diminuindo-se gradualmente a idade de lodo até que se observe que a nitrificação não ocorre mais (van Haandel e Marais, 1999). Neste momento adota-se que em Equação (1) o denominador se torna zero (por isso cessa a nitrificação) e determina-se a constante $\mu_{\mathrm{m}}$, apresentada na Equação (2).

$\mu_{\mathrm{m}}-\left(\mathrm{b}_{\mathrm{n}}+1 / \mathrm{R}_{\mathrm{sm}}\right)=0$

$\mu_{\mathrm{m}}=\mathrm{b}_{\mathrm{n}}+1 / \mathrm{R}_{\mathrm{sm}}$

onde:

$\mathrm{R}_{\mathrm{sm}}$ = idade de lodo mínima para manter a nitrificação (d).

Este método é tecnicamente factível mas muito laborioso, levando-se semanas e até meses para uma determinação. Por esta razão, propõe-se um método que utiliza a respirometria como ferramenta para determinar experimentalmente a constante $\mu_{\mathrm{m}}$.

Quando se aplica aeração a uma batelada de lodo sem alimentação, a tendência da Taxa de Consumo de Oxigênio (TCO) é de se tornar constante, compatível com a taxa de respiração endógena. Nestas condições, quando se adiciona uma quantidade de amônia ou nitrito, as bactérias nitrificadoras irão agir e observam-se imediatamente os resultados desta atividade: aumento da TCO, da concentração de nitrato e diminuição da concentração de amônia e da alcalinidade. Normalmente, não se observa um aumento da concentração de nitrito porque este composto é oxidado rapidamente para nitrato pelas Nitrobacter. A oxidação de amônia para nitrato pode ser escrita como:

$$
\mathrm{NH}_{3}+2 \mathrm{O}_{2} \rightarrow \mathrm{NO}_{3}^{-}+\mathrm{H}_{2} \mathrm{O}+\mathrm{H}^{+}
$$

Pela estequiometria da oxidação de amônia para nitrato, tem-se que a taxa de nitrificação é relação direta da taxa de consumo de oxigênio para o processo, como apresentado na Equação (3).

$\mathrm{r}_{\mathrm{N}}=-\mathrm{r}_{\mathrm{a}}=\mathrm{r}_{\mathrm{ni}}=-\mathrm{r}_{\mathrm{alc}} / 7,14=\mathrm{TCO}_{\mathrm{n}} / 4,57$

onde:

$\mathrm{r}_{\mathrm{N}}=$ taxa de nitrificação $\left(\mathrm{mg} \cdot \mathrm{l}^{-1} \cdot \mathrm{h}^{-1}\right)$

$r_{a}=$ taxa de consumo de amônia $\left(\mathrm{mg} \cdot \mathrm{l}^{-1} \cdot \mathrm{h}^{-1}\right)$

$\mathrm{r}_{\mathrm{ni}}=$ taxa de produção de nitrito $\left(\mathrm{mg} . \mathrm{l}^{-1} \cdot \mathrm{h}^{-1}\right)$

$r_{\text {alc }}=$ taxa de diminuição de alcalinidade $\left(\mathrm{mg} \mathrm{CaCO} \cdot \mathrm{l}^{-1} \cdot \mathrm{h}^{-1}\right)$

$\mathrm{TCO}_{\mathrm{n}}=$ taxa de consumo de oxigênio para nitrificação $\left(\mathrm{mgO} \cdot \mathrm{l}^{-1} \cdot \mathrm{d}^{-1}\right)$

De todas as variáveis, somente a TCO pode ser medida continuamente em testes sem destruição de amostra e, por esta razão, torna-se a melhor para acompanhar o processo de nitrificação com taxa variável.

A técnica de determinação da constante $\mu \mathrm{m}$ tem as seguintes etapas:

Etapa 1: É dada por van Haandel e Marais (1999), em que se desenvolve um lodo em um sistema de lodo ativado, alimentando-o com vazão e carga constante e idade de lodo determinada. Nestas condições a concentração de Nitrosomonas é dada pela Equação (4).

$\mathrm{X}_{\mathrm{n}}=\mathrm{Y}_{\mathrm{n}} \mathrm{R}_{\mathrm{s}} \mathrm{N}_{\mathrm{c}} /\left(1+\mathrm{b}_{\mathrm{n}} \mathrm{R}_{\mathrm{s}}\right) / \mathrm{R}_{\mathrm{n}}$

onde:

$\mathrm{X}_{\mathrm{n}}=$ concentração de Nitrosomonas $\left(\mathrm{mgSVS} . \mathrm{l}^{-1}\right)$

$\mathrm{Y}=$ coeficiente de rendimento de Nitrosomonas (mgSVS.mg-1 DQO)

$\mathrm{N}$ = concentração de amônia nitrificada no sistema de tratamento $\left(\mathrm{mgN} . \mathrm{l}^{-1}\right)$

$\mathrm{R}_{\mathrm{h}}=$ tempo de permanência hidráulica no sistema de tratamento $(\mathrm{d})$

Etapa 2: Separa-se uma batelada deste lodo, aerando-a até que a TCO se torne essencialmente constante, equivalente à taxa de respiração endógena.

Etapa 3: Aplica-se uma determinada concentração de amônia, suficiente para que a nitrificação se desenvolva à taxa máxima $\left(\mathrm{N}_{\mathrm{a}}>>\mathrm{K}_{\mathrm{n}}\right)$.

Etapa 4: Determina-se a taxa máxima da TCO. A Figura 2 mostra um respirograma (TCO em função do tempo) típico para a atividade das bactérias Nitrosomonas (área 1) e bactérias Nitrobacter (área 2).

A constante $\mu_{\mathrm{m}}$ é então dada pela equação (5):

$$
\begin{aligned}
& \mu_{\mathrm{m}}=\mathrm{Y}_{\mathrm{n}} \mathrm{r}_{\mathrm{N}, \max } / \mathrm{X}_{\mathrm{n}}= \\
& =\left(\mathrm{TCO}_{\mathrm{n}, \max } / 4,57\right)\left(1+\mathrm{b}_{\mathrm{n}} \mathrm{R}_{\mathrm{s}}\right)\left(\mathrm{R}_{\mathrm{h}} / \mathrm{N}_{\mathrm{c}} \mathrm{R}_{\mathrm{s}}\right)
\end{aligned}
$$




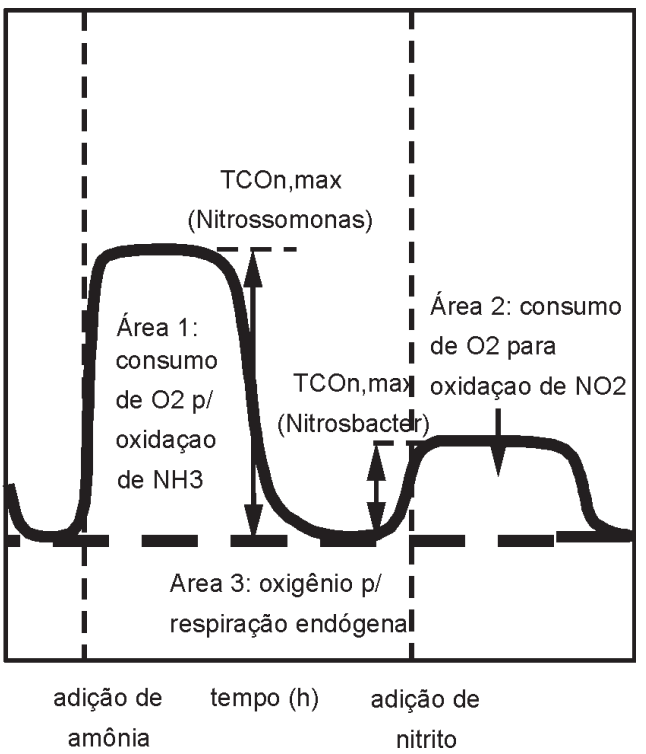

Figura 2 - Respirograma típico com substrato amônia seguido por nitrito

Quando se deseja determinar a constante de crescimento máxima de Nitrobacter em vez de Nitrosomonas, aplica-se simplesmente o substrato nitrito (na forma de solução de nitrito de sódio, por exemplo) em vez do substrato amônia. Neste caso, a estequiometria diz que a constante de proporcionalidade da taxa de oxidação de nitrito e a taxa de consumo de oxigênio é de $1,21 \mathrm{mgO} / \mathrm{mgN}$.

A técnica respirométrica de determinação da cinética de nitrificação foi aplicada para determinar a influência do $\mathrm{pH}$ sobre o valor da constante $\mu \mathrm{m}$ tanto para Nitrosomonas como para Nitrobacter. Para tanto, adicionou-se ácido ou base para estabelecer um determinado $\mathrm{pH}$ desejado na faixa de $5 \mathrm{a}$ 8,5 e depois se aplicou o procedimento experimental citado acima.

\section{RESULTADOS E DISCUSSÕES}

\section{Atividade das bactérias heterotróficas}

Com base na concentração do lodo, foi verificada a TCO endógena teórica. $\mathrm{O}$ valor encontrado foi de $15,2 \mathrm{mg} / \mathrm{l} / \mathrm{h}$, o qual se apresenta bem próximo àquele determinado pelo respirômetro, de $14,3 \mathrm{mg} / \mathrm{l} / \mathrm{h}$, o que garante a confiabilidade do teste.

Na Figura 3 observa-se o resultado das TCO relativo à respiração endógena após interrupção da aeração de 1, 15 e 30 dias de duração. É possível verificar que, apesar da amostra ter sido aerada antes do experimento, há material extracelular que se gera durante a interrupção da aeração. Isto se conclui a partir da TCO elevada que se observa nos primeiros momentos depois do reinício da aeração. Esta geração se explica quando se admite que há bactérias morrendo e se solubilizando (lise), mas que este material (biodegradável) não pode ser usado pelas bactérias vivas porque não há disponibilidade de um oxidante. Quando a aeração é reiniciada, a massa bacteriana viva metaboliza a massa de bactérias mortas. Quando a interrupção é curta (no primeiro dia), há pouco material extracelular e o consumo se dá rapidamente (100 min, Figura 3), restabelecendo-se basicamente a TCO da respiração antes da interrupção da aeração. Todavia, para interrupçóes longas (15 dias), a lise do material orgânico é muito mais expressiva, resultando num maior aumento temporário da TCO e por um período mais longo; mas, no fim do metabolismo do material gerado nos 15 dias (400 min, Figura 3), a TCO se restabelece a um nível nitidamente inferior ao valor inicial da TCO: 10,2 contra $14,3 \mathrm{mg} / \mathrm{l} / \mathrm{h}$. Observa-se que neste intervalo houve decaimento de aproximadamente $1-10,2 / 14,3=1 / 3 \mathrm{da}$ massa de bactérias vivas. No trigésimo e último dia do experimento, tanto o valor logo depois do reinício da aeração como a TCO correspondente à respiração endógena são baixas. $\mathrm{O}$ baixo valor inicial pode ser explicado se a atividade do lodo vivo for baixa, fato que é comprovado pelo teste específico correspondente. O baixo valor da TCO de respiração endógena ( $4 \mathrm{mg} / \mathrm{l} / \mathrm{h}$ ) mostra que grande parte das bactérias vivas decaiu nos trinta dias sem aeração, mantendo-se uma fração viva de somente 4/14,3 = 0,28.

$\mathrm{Na}$ Figura 4, observa-se a evolução da TCO de respiração endógena em função da duração da interrupção da aeração. Como se vê na figura, a TCO endógena não apresenta grandes variações nos primeiros vinte dias sem aeração. Após esse período, verifica-se um decréscimo considerável da mesma, o que caracteriza um decaimento da massa bacteriana.

A Figura 5 apresenta como exemplos os resultados da TCO obtidos em amostras submetidas a períodos de 1, 16 e 30 dias sem aeração, sendo adicionado à mesma, após obtenção da TCO endógena, um substrato solúvel: acetato de sódio. Observa-se no primeiro dia uma TCO (que representa a TCO endógena) de aproximadamente $14,3 \mathrm{mg} / \mathrm{l} / \mathrm{h} \mathrm{e}$, após a adição do acetato, atinge o valor médio de 53,0 mg/l/h alcançando sua máxima TCO e, conseqüentemente, a máxima atividade bacteriana. Após total consumo do acetato, há uma brusca queda da TCO, obtendo-se, assim, uma estabilização da mesma, o que representa uma segunda TCO endógena ligeiramente superior à primeira. Isso provavelmente se deve ao crescimento da massa bacteriana ao metabolizar o substrato. Após quinze dias sem aeração já é possível observar uma queda da atividade (em torno de $25 \%$ ), tendo-se no último dia de experimento uma baixa de $50 \%$ na atividade bacteriana, o que é bastante representativo.

A Figura 6 apresenta a proporção entre a TCO máxima (com substrato orgânico abundante) e a TCO mínima (relativa à respiração endógena) em função do período sem aeração. Observa-se que a proporção tende a diminuir com o tempo, o que indica que a atividade específica (isto é, a capacidade metabólica do lodo por unidade de massa de lodo vivo) diminui na medida em que aumenta o tempo de interrupção de aeração. Esta diminuição se torna mais acentuada depois de 20 dias de interrupção da aeração.

A atividade das bactérias nitrificantes é observada na Figura 7. Os resultados foram obtidos em amostras submetidas a 1,15 e 30 dias sem aera- 


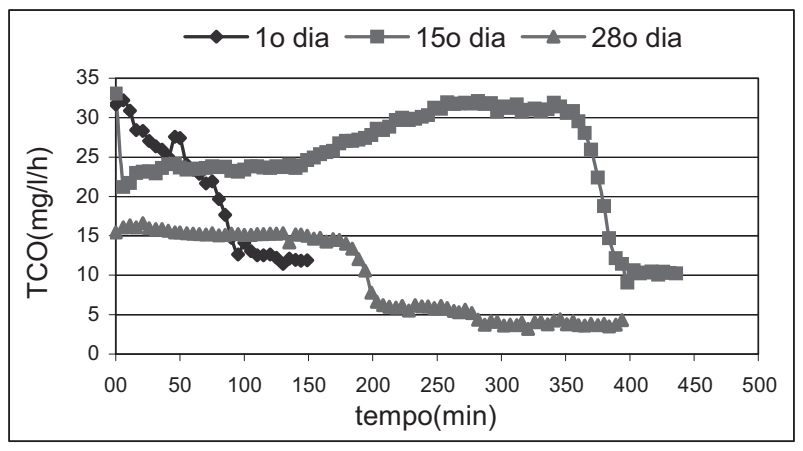

Figura 3 - Perfis da TCO do licor misto em diferentes períodos sem aeração

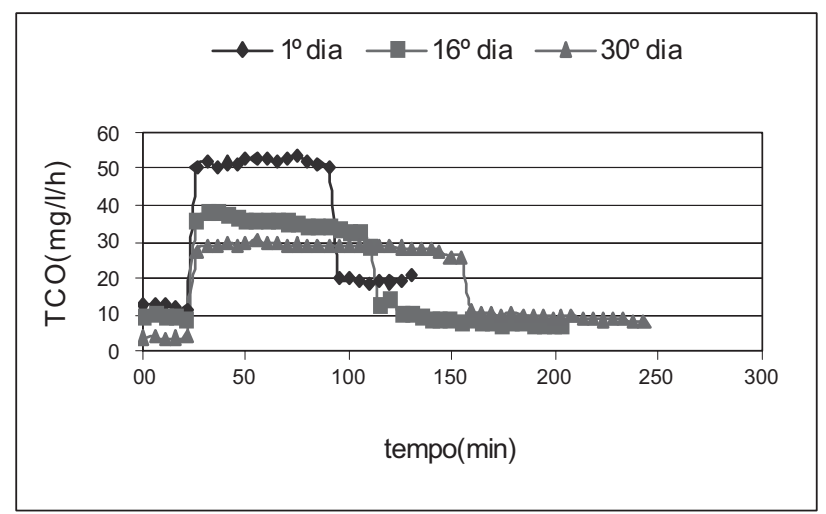

Figura 5 - Perfis da TCO do licor misto em diferentes períodos sem aeração e após a adição de alimento solúvel

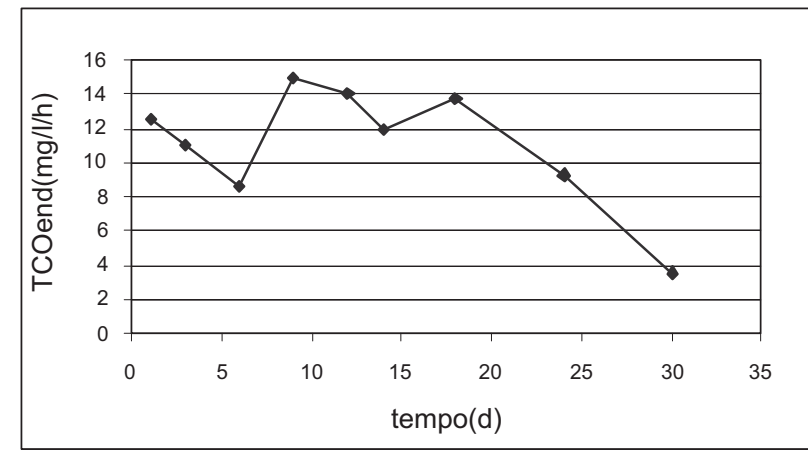

Figura 4 - Valor da respiração endógena em bateladas de uma amostra de lodo após vários períodos sem aeração

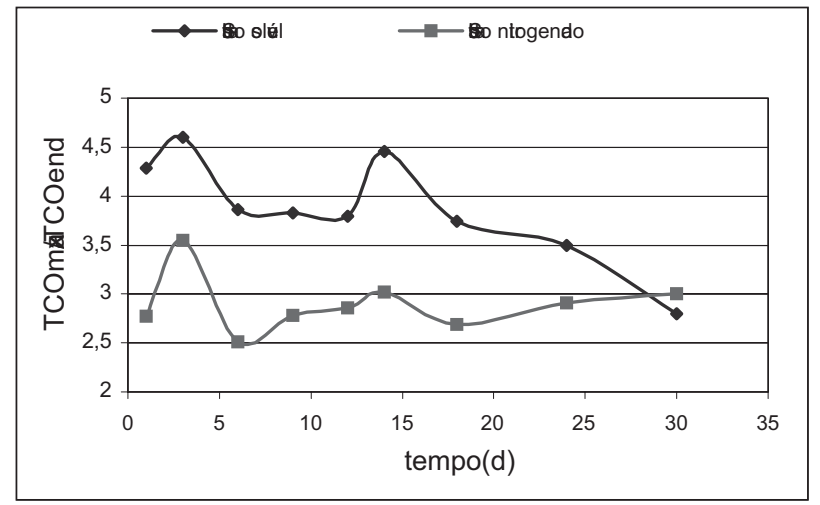

Figura 6 - Proporção entre o valor máximo da TCO e a respiração endógena para dois substratos em função da duração da interrupção da aeração ção, sendo adicionado ao licor misto um material nitrogenado (cloreto de amônio) como alimento para posterior verificação da atividade das bactérias nitrificantes. É possível observar que, diferentemente das bactérias heterotróficas, as autotróficas apresentaram uma maior resistência à falta de oxigênio, praticamente não havendo alteração da TCO máxima: a TCO logo depois da adição de amônia diminuiu de $45 \mathrm{mg} / \mathrm{l} / \mathrm{h}$ no primeiro dia sem aeração para $40 \mathrm{mg} / \mathrm{l} / \mathrm{h}$ após 30 dias sem aeração. Outro fato importante é que a TCO diminuía gradualmente, enquanto o lodo metabolizava a amônia adicionada. Isto se deve ao fato de que a nitrificação é um processo que consome alcalinidade e, por esta razão, o $\mathrm{pH}$ diminui, o que em si reduz a taxa de nitrificação e, portanto, a TCO associada a este processo. É interessante observar que a diminuição do $\mathrm{pH}$ leva também a uma redução da taxa de respiração endógena quando o metabolismo da amônia está concluído.

\section{Atividade das bactérias autotróficas}

O procedimento respirométrico foi usado primeiramente para fazer um balanço de massa em que a quantidade de oxigênio utilizada na nitrificação foi comparada com a massa de amônia ou nitrito adicionada à batelada de lodo. Por este meio, foi possível calcular a fração de amônia ou nitrito que foi efetivamente oxidada. Os resultados estão 'plotados' em função do $\mathrm{pH}$ na Figura 8 para amônia (a) e para nitrito (b). Observa-se que na faixa neutra a oxidação do substrato é eficiente, superando os 90 $\%$; mas, para $\mathrm{pH}$ baixo a eficiência de oxidação diminui drasticamente.

Com auxílio dos dados da taxa máxima de consumo de oxigênio e da concentração de Nitrosomoas e Nitrobacter na amostra de lodo, calculou-se em função do $\mathrm{pH}$ a taxa máxima de crescimento das bactérias nitrificantes. $\mathrm{Na}$ Figura 9, apresenta-se o resultado. Observa-se que a taxa máxima de crescimento de Nitrosomonas é menor que a de Nitrobacter, exceto para o $\mathrm{pH}=8,5$. Este resultado é compatível com o fato de que normalmente a taxa de crescimento de Nitrosomonas limita a taxa de nitrificação em sistemas de lodo ativado. Os valores numéricos das constantes são compatíveis com aquelas encontradas na literatura, com valores de $0,4 \mathrm{~d}^{-1}$ (van Haandel e Marais, 1999) a $0,94 \mathrm{~d}^{-1}$ (Lijklema, 1973).

\section{CONCLUSÕES}

(1) A respirometria mostrou-se uma ferramenta muito útil para avaliar a sobrevivência e a capacidade metabólica do lodo ativado quando a aeração é interrompida, além de uma ferramenta confiável e prática para avaliar a cinética de nitrificação em sistemas de lodo ativado;

(2) Grande parte das bactérias no lodo de um sistema Bardenpho operado com esgoto municipal como afluente sobrevive por períodos de até 2 semanas sem aeração. Após um período de 3 se- 


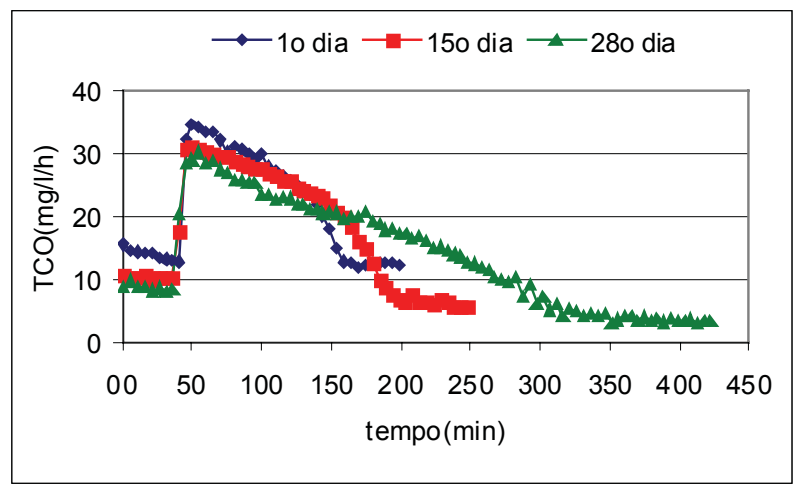

Figura. 7 - Perfis da TCO do licor misto em diferentes períodos sem aeração e após a adição de alimento solúvel

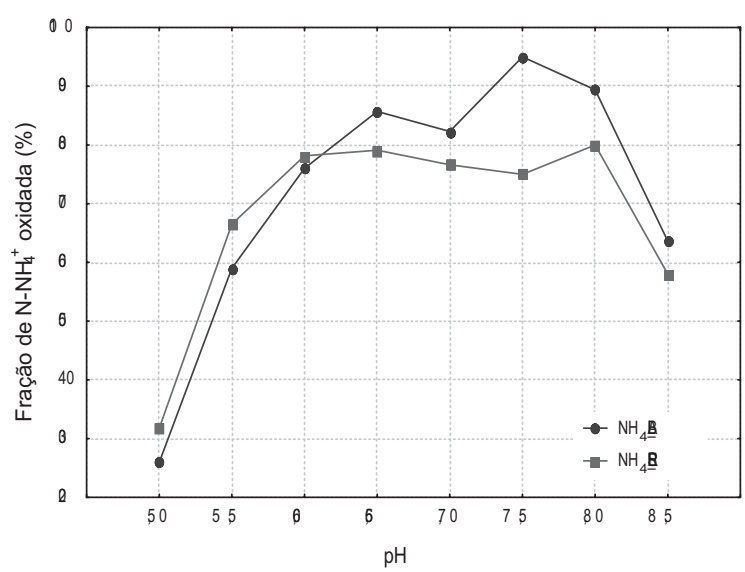

(a)

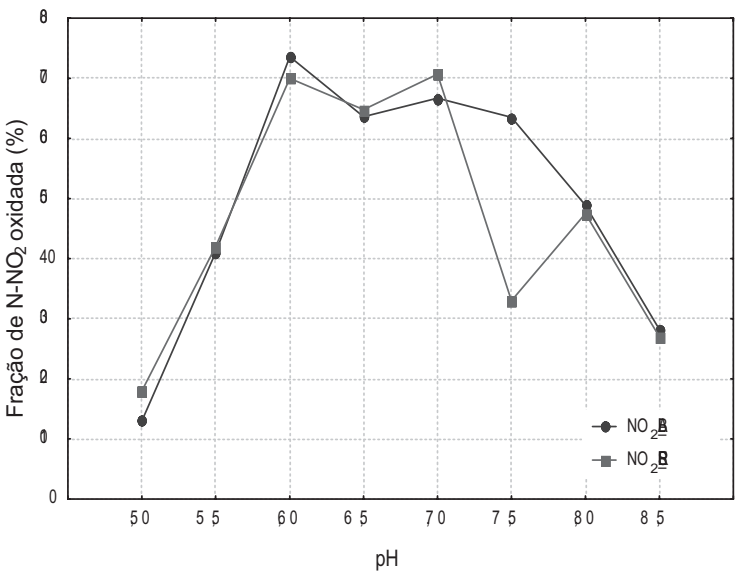

$($ D

Fiura 8 - Fração de nitrogênio oxidada pelas (a) Nitrosomonas e (b) Nitrobacter, nos pHs estudados

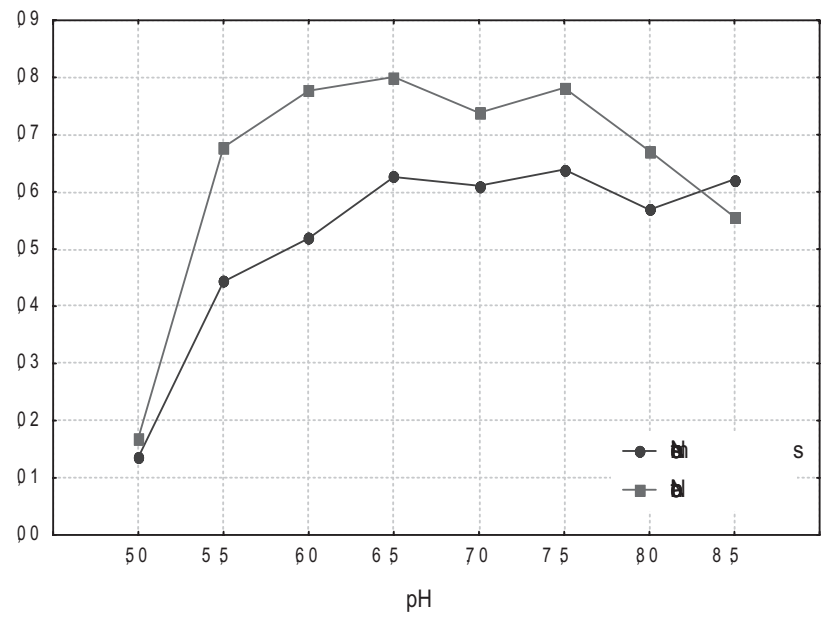

Figura 9 - Taxa específica máxima de crescimento das Nitrosomonas e Nitrobacter na faixa de $\mathrm{pH}$ estudada 
manas começa a haver um decaimento expressivo da fração de lodo ativo.

(3) A capacidade metabólica sofre uma redução gradual na medida em que se aplica um período mais longo sem aeração, principalmente porque a massa de bactérias vivas diminui.

(4) A atividade específica das bactérias heterotróficas permaneceu praticamente constante durante 20 dias quando se aplicavam períodos de até 20 dias sem aeração, e diminuía em aproximadamente $50 \%$ quando o período se estendia por 30 dias. A atividade específica das bactérias autotróficas não foi mensuravelmente afetada por períodos de até 30 dias sem aeração.

(5) $\mathrm{O} \mathrm{pH}$ influenciou diretamente a atividade de ambas as nitrificantes. Para $\mathrm{pH}$ na faixa neutra foram observadas as taxas máximas de oxidação. para $\mathrm{pH}$ ácido as Nitrosomonas demonstraram maior inibição e para $\mathrm{pH}$ alcalino as Nitrobacter tiveram sua capacidade oxidativa mais comprometida;

(6) As Nitrobacter foram capazes de oxidar o nitrito a uma taxa mais elevada que as Nitrosomonas oxidaram a amônia, na faixa de $\mathrm{pH}$ estudada, e, conseqüientemente, tiveram também maiores taxas máximas de crescimento específico.

\section{REFERÊNCIAS}

CATUNDA S.Y.C, et al. Método de medição contínua da Taxa de Respiração em sistemas de Lodo Ativado, In: XI CONGRESSO BRASILEIRO DE AUTOMÁTICA, São Paulo, S.P. 269-274. 1996.

DOLD, P.L., EKAMA, G.A. AND MARAIS, G.V.R. A General Model for the Activated Sludge Process, Prog.Wat.Tech., 12, 47-77. 1980.

DOWNING, A.L., PAINTER, H.A. EKNOWLES, G. Nitrification in the Activated Sludge Process, J. Proc. Inst. Sew. Purif., 64,2 pp 130-158. 1964.

DOWNING, A.L., TOMILINSON., T.G. e TRUESDALE, G.A. Effects of Inhibitors on Nitrification in the Activated Sludge Process, J. Proc. Inst. Sew. Purif., 6, pp 537-558. 1964.

HENZE, M. et al. Activated sludge model $N^{o} 1$ Scientific and Technical reports No 1, IAWPRC, London, Reino Unido. 1986.

HENZE, M. et al. Activated sludge model $N^{\circ} 2$, IAWQ, London, Reino Unido. 1994.

LIJKLEMA, L. Model for Nitrification in the Actived Sludge Process. Envir. Sci and Tech. 1973.

MCCARTY, P.L. E BRODERSEN C.F. Theory and extebded aeration activated sludge. J. Wat. Pollut. Control Fed. 34, 11 1095-1103. 1962.

SPANJERS H. et al. Respirometry in control of the activated sludge process Wat. Sci. Tech, 34, (117-126). 1996.

VAN HAANDEL, A.C. E CATUNDA, P.F.C. Determinação da Taxa de Consumo de Oxigênio. Revista Engenharia Sanitária. 21, 4, pp.481488. 1982.
VAN HAANDEL, A.C. E CATUNDA, P.F.C. O balanço de massa em sistemas de tratamento com lodo em suspensão. Revista Engenharia Sanitária. 22, 4, pp.409-413. 1983.

VAN HAANDEL, A.C; CATUNDA P.F.C. E NEIVA M.R. Um método experimental para a determinação da eficiência de aeradores superficiais em sistemas de lodo ativado. In: $19^{\circ}$ CONGRESSO BRASILEIRO DE ENGENHARIA SANITÁRIA E AMBIENTAL, Foz de Iguaçu. 1997.

VAN HAANDEL, A. C. e MARAIS, G. O Comportamento do Sistema de Lodo Ativado: Teoria e Aplicaçōes para Projetos e Operaçôes. 1999.

Endereço para correspondência:

\section{Adriana Guimarães Costa}

Centro Federal de Educação

Tecnológica do Pará (CEFET-PA)

Departamento de Meio Ambiente

Av. Almirante Barroso, I I55

Bairro Marco

66000-000 Belém - PA - Brasil

Tel.: (9I) 3229-2779 - 8II2-6I5I

E-mail: adriana.gc@cefetpa.br;

engedri@yahoo.com.br

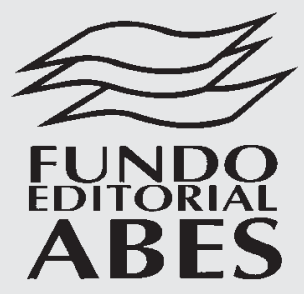

LOJA DE LIVROS ESPECIALIZADA EM SANEAMENTO E MEIO AMBIENTE 